This item was submitted to Loughborough's Research Repository by the author.

Items in Figshare are protected by copyright, with all rights reserved, unless otherwise indicated.

\title{
Determining of the role of ventilation in residential energy demand reduction using a heat-balance approach
}

PLEASE CITE THE PUBLISHED VERSION

https://doi.org/10.1016/j.buildenv.2018.08.053

PUBLISHER

Elsevier

VERSION

AM (Accepted Manuscript)

\section{PUBLISHER STATEMENT}

This paper was accepted for publication in the journal Building and Environment and the definitive published version is available at https://doi.org/10.1016/j.buildenv.2018.08.053.

LICENCE

CC BY-NC-ND 4.0

\section{REPOSITORY RECORD}

Cosar-Jorda, Paula, Richard Buswell, and Val Mitchell. 2018. "Determining of the Role of Ventilation in Residential Energy Demand Reduction Using a Heat-balance Approach". Loughborough University. https://hdl.handle.net/2134/34794. 


\title{
Determining of the role of ventilation in residential energy demand reduction using a heat-balance approach
}

\author{
P. Cosar-Jorda \\ School of Architecture, Building and Civil Engineering, Loughborough University, UK \\ R. A. Buswell ${ }^{1}$ \\ School of Architecture, Building and Civil Engineering, Loughborough University, UK \\ V. A. Mitchell \\ Loughborough Design School, Loughborough University, UK
}

\begin{abstract}
Ventilation in domestic buildings can have a significant impact on energy consumption but it is notoriously difficult to quantify, requiring physical test methods that are cumbersome and costly to apply. Energy demand reduction analyses routinely neglect the impact of ventilation and so offering well balanced advice for specific households is not possible. This paper describes a simple steady-state, heat-balance calculation method that is supplemented with monitoring data to model the effectiveness of reducing ventilation rates to minimum standards for individual homes. A key step is to determine the daily mean air change rate and the method is shown to yield plausible estimates that can then be used to establish the impact on energy demand. The benefits of the approach include improved energy demand dissargregation, customised energy demand reduction assessment and offers a means to underpin the development of better models of ventilation for building performance analysis.
\end{abstract}

Keywords: Smart home, heat balance, window opening, energy demand reduction, Indoor Air Quality

\footnotetext{
${ }^{1}$ Corresponding authour - email address: r.a.buswell@lboro.ac.uk
} 


\section{Introduction}

Decreasing domestic energy demand in the UK is a key component in reducing $\mathrm{CO}_{2}$ emissions and providing energy security (Baruah et al. 2014). 29\% of the national demand can be attributed to the domestic sector (DECC, 2017)

5 and the UK is set to increase the electrification of heat supplied through resistive heating and heat-pump systems (Clegg and Mancarella, 2018). The reduction of energy demand will continue to apply to electrified systems and from the householders perspective, probably more so during the transition as electricity costs for energy are likely to increase (Baruah et al., 2014). The appetite for economy in the home may well increase alongside the need for greater control of demand (Eyre and Baruah, 2014).

Space-heating generates the largest demand for energy in the domestic buildings (DECC, 2017). Ventilation is responsible for a significant proportion of this (Southall, 2018), but it is also a critical factor in the provision of comfortable and healthy indoor environments (Chenari et al. 2016). Implementing the trade-off between energy demand and indoor air quality presents a conundrum to householders who currently have no simple methods available with which to judge the cause and effect of control actions. Enabling the provision of insightful feedback to support better decision making is therefore an important and useful step forward, but one that has not been fully addressed (Wilson et al., 2013 Hargreaves, 2018).

Interest in the assessment of ventilation began in the 1930's and remains the subject of contemporary research (Persily, 2016, Carrilho et al., 2016, Gough et al., 2018), however the spotlight typically falls on the measurement of venti-

25 lation rate, rather than the impact of ventilation on energy demand. Common measurement techniques include the blower door test (Lipschultz, 1981; Coxon, 2013), the use of tracer gas (Marley, 1935; Warner, 1940, ISO, 2012), and more recent approaches such as steady-state analysis of $\mathrm{CO}_{2}$ concentrations (Persily, 1997, ASTM, 2012).

Field measurements are expensive to deploy, even with the development of 
low cost tracer gas methods. They are intrusive and the reliability of these approaches has been questioned (Grot, 1979, Dietz et al., 1986, Sherman, 1989). Studies are often limited providing a snapshot of information relating to infiltration and ventilation rates, rather than characterisation over a wide range of 35 building operating conditions (Zhai et al. 2015, Omrani et al., 2017).

Modelling techniques have been used to study dependency of air change rates on temperature difference, wind speed and window opening (Dick et al. 1949: Liu et al. 2018). They can be applied to provide airflow and thermal load information by application of Computational Fluid Dynamics, but are often 40 limited by the application of fixed boundary conditions (Djunaedy et al., 2003). Common building simulation tools are known to be limited when modelling naturally ventilated buildings where the occupant plays a significant role in determining window operation, effecting the reliability of energy consumption estimates (Carrilho et al. 2016, Yu et al., 2011). None of these methods are 45 practical to implement in residential buildings en masse and all have limited capacity to accurately represent the air flow in real buildings even with lengthly calibration procedures.

To complicate matters, natural ventilation in domestic buildings results in time varying flow rates which may not be delivered along intended paths through

50 the building, potentially reducing the effectiveness of ventilation and increasing heat losses (Southall, 2018). The human is a complicated actor in the ventilation control system, where reliable cause and effect relationships between temperatures (for example) and actions are often absent (Chenari et al., 2016). Indeed, anthropological-based energy demand reduction research (Shove and Warde, 2002 Pink et al. 2015) evidences the social and circumstantial complexity that overlays more traditional notions of the occupant as an actuator of control as inferred by work such as that of Yun and Steemers (2008), Haldi and Robinson (2011) and Wei et al. (2014).

The ability to evaluate the Air Change Rates (ACRs) in a building has value 60 for the improvement of building energy modelling, providing insight indicators for indoor air quality and for the disaggregation of energy demand. The latter 
case is particularly important when trying to engage householders to moderate/change 'behaviour' (or the way in which they do things), to routines or practices that might lead to a reduction in their energy consumption.

Providing feedback has been demonstrated to yield significant variation in effectiveness (Abrahamse et al., 2007, Abrahamse and Steg, 2009), even to the point of being counterproductive (Herrero et al. 2018). The challenge is to enable the householder to relate their actions to the resultant energy demand, which is more likely to be improved using personalised information (Hargreaves, 2018). The assessment of the impact of ventilation forms a key component in this because heat flow through air exchange is difficult to comprehend to the non-specialist. The problem of quantifying the impact of ACR on energy consumption requires non-intrusive methods for its estimation under normal conditions in the home, such that the influence of the occupant on energy demand through the operation of systems can be implicitly captured over varying environmental conditions and then effectively relayed to the occupant.

Building on previous work (Cosar-Jorda and Buswell, 2015), this paper demonstrates the feasibility of using a new hybrid-heat balance (HHB) approach to do this. It combines steady-state modeling with monitoring data to generate estimates of daily mean ACR which can make use of smart-meter data, supplemented with common smart-home measurements. The paper describes the method, verifies the estimates of ACR generated with established norms and then applies the approach to creating indicators of the impact of ACR on energy consumption and potential for energy demand reduction, customised for individual households.

\section{The Hybrid-Heat Balance (HHB) approach}

Buildings are dynamic thermal systems driven by environmental conditions that vary. They are effected by the gains from heating, hot-water and electrical systems, occupants and the interaction of ACR through stack effect, wind effect, mechanical systems and the associated pressure and resistance characteristics 
of gaps, cracks, windows, doors, ducts and vents. The thermal mass of the building plays a significant role in heat storage and all of these factors combine through time constants that vary from the order of seconds to days to yield the observable building energy performance characteristics.

A common assumption used to simplify calculations is to consider steadystate conditions, where all driving inputs that affect the heat flow between the building and the external environment do not change with time. In addition, if the assumption is made that all heat gains are evenly distributed throughout the building, and that the internal temperatures are uniform in all zones, then over a period of time over 24 hours the heat transfer through the fabric will approach steady-state (CIBSE, 2006). Under these conditions, a building can be modelled as a single zone and yields the following relationship (CIBSE, 2006),

$$
r=Q_{g}+Q_{e}+Q_{s}+Q_{p}+Q_{f}+Q_{v}
$$

where $Q_{g}$, represents the heat gain from space-heating from all sources, central heating systems, stand alone fires etc. $Q_{e}$ are the heat gains from all appliances and electrical heating appliances. $Q_{p}$ and $Q_{s}$ are the heat gains from the occupants and solar heat gain through the windows. $Q_{f}$ and $Q_{v}$ are the heat gains through the building fabric and ventilation. $r$ is the residual and if we assume steady-state conditions, then the heat stored in the thermal mass is constant and $r=0$.

The heat balance is applied to sensible heat only and the assumption is that there is little difference between indoor and outdoor humidity (comparing daily average values) and hence the latent component of the total heat transfer is neglected. This will be the case in an empty building where there are no processes that generate water vapour (bathing and cooking for example). In the real case, the occupancy will vary and bathing will take place over relatively short periods and are intermittent over the day. Bathing and showering will produce the greatest amount of water vapour and hence the largest input of latent heat, but typically this is contained within the bathroom and extracted 
via mechanical means and so it will have little effect on the bulk-average daily mean indoor air temperature in the building.

The heat balance is performed using daily mean or total values (dependent on the variable). This assumes that there are no effects from the thermal storage of the fabric over a 24 hour period, which is reasonable when the space-heating system is operational, after the initial two or three days after its activation. At this time the building fabric has absorbed enough heat to dampen the effect of heat storage: over the 24 hour period, it will release heat when the heating system is switched off and recharge once it is activated. Our observations support this for consecutive days of use when the heating is on for two or three substantial periods in the day as is the norm in UK households (Kane et al. 130 2015).

It is important that all sources of heating are captured and where these are either fueled by metered gas or electricity in order for the the method to accurately account for the heat input. Care must be taken where standalone LPG or solid fuel heating devices are used, as these will generate heat input that cannot be readily quantified. Food preparation, whether electric or gas, will result in sensible heat input to the space: generally cooking is a fairly small fraction of the energy used for heat (nationally in the UK around $2 \%$ (BEIS, 2017)).

All parameters of the model can be estimated using established relationships that are adapted to region: for example in the UK the BREDEM model (Henderson and Hart, 2012) provides a baseline set of assumptions and models that can be used to characterise a building. It will however yield a very generic representation of a specific building because of the generalised assumptions contained within it. The idea behind the HHB method proposed here, is to replace assumptions with calculated values using local weather data, smart meter and/or 'smart home' measurements from a specific home to create a more accurate representation of the household's energy use. 


\subsection{Description of model parameters}

In this work, $Q_{g}$ is derived from daily metered gas consumption. The me-

acteristics and the standard values used in the BREDEM modelling tool (Henderson and Hart, 2012).

$Q_{p}$ was estimated based on self-reported daily occupancy patterns and an assumed metabolic rate based on the occupant age and gender, CIBSE (2005).

$Q_{f}$ was calculated assuming U-values based on the construction ascertained through inspection. A site survey yielded dimensions and fabric upgrades such as double glazing, loft and cavity wall insulation. The driving temperatures in the calculation were daily averages, established from the local MIDAS weather 
station and the bulk-average daily mean indoor air temperature in each house, derived from measurements in several rooms. The measurements, model parameters and their sources are summarised in Table 1.

Table 1: Measurements and model parameters used in the HHB method.

\begin{tabular}{|c|c|}
\hline Parameters & Approach and reference. \\
\hline \multicolumn{2}{|c|}{ Gas (space heating and hot water supply) } \\
\hline Gas volume & Measured \\
\hline Gas calorific value & \multirow{2}{*}{$\begin{array}{l}\text { Taken from the gas supplier, National Grid } 2013 \text { Nationalgrid, 2018, } \\
\text { Measured }\end{array}$} \\
\hline Hot water volume & \\
\hline Cold water temperature & Measured \\
\hline Hot water temperature leaving the boiler & Measured \\
\hline Water heat capacity & Constant \\
\hline Boiler efficiency & Taken from SEDBUK based on boiler model HHG, 2018. \\
\hline Drain water temperature & Taken from previous LEEDR work, based on ambient conditions Buswell, 2013, \\
\hline \multicolumn{2}{|l|}{ Electric input } \\
\hline Power & Measured \\
\hline Heat gain & Assumed for steady-state conditions based on previous work Hosni et al., 1999, \\
\hline \multicolumn{2}{|l|}{ Solar gains } \\
\hline Vertical solar flux & \multirow{3}{*}{\begin{tabular}{r|r} 
Taken from BREDEM based on location & Henderson and Hart, 2012 \\
\cline { 2 - 2 } Taken from BREDEM based on glazing orientation & Henderson and Hart, 2012 \\
Collected from local MIDAS weather station
\end{tabular}} \\
\hline Conversion factor & \\
\hline Solar Radiation & \\
\hline Frame Factor & Taken from BREDEM based on frame type Henderson and Hart, 2012. \\
\hline Glazing transmission factor & Taken from BREDEM based on glazing type Henderson and Hart, 2012, \\
\hline Windows area & Site measurement \\
\hline Orientation & Taken from Google Earth based on building position \\
\hline Latitude & Taken from Google earth \\
\hline Monthly solar declination & Taken from BREDEM based on the month of study Henderson and Hart, 2012 \\
\hline \multicolumn{2}{|l|}{ Occupants } \\
\hline Metabolic factor & \multirow{2}{*}{ 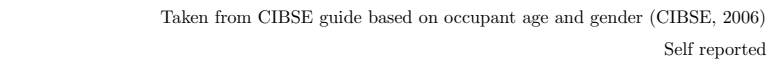 } \\
\hline Number of occupants & \\
\hline Occupied time & Self reported schedule \\
\hline \multicolumn{2}{|l|}{ Fabric } \\
\hline Building element transmittance & \multirow{2}{*}{$\begin{array}{cc}\text { Taken from Building Standards based on building elements' characteristics } & \text { BEng et al., 2003 } \\
\text { Site measurement }\end{array}$} \\
\hline Building element area & \\
\hline Indoor air Temperature & Calculated from available room measurements \\
\hline Outdoor air Temperature & Collected from local MIDAS weather station \\
\hline Dwelling floor area & Site measurement \\
\hline
\end{tabular}




\subsection{Estimating ACR}

Once the above parameters have been established the only unknown is the heat flow via air exchange with the outside. $Q_{v}(\mathrm{kWh})$ is the daily heat gain this work the assessment was carried out over 365 days. The daily mean ACR $\bar{N}\left(\mathrm{~h}^{-1}\right)$, can then be estimated by,

$$
\bar{N}=\frac{3 Q_{v}}{24 V\left(\bar{\theta}_{a i}-\bar{\theta}_{t a o}\right)},
$$

where $V$ is the volume of the house $\left(\mathrm{m}^{3}\right), \bar{\theta}_{a i}$ and $\bar{\theta}_{t a o}$ are the bulk mean, daily average indoor air temperature and the daily average outdoor air temperature

190

\subsection{Measurement and monitoring}

The dataset that supports this work together with a full description of the measurement devices, calibration details, data visualisation etc. can be freely downloaded (Buswell et al., 2018). The data from 2013 was used in this study less (Zigbee) system which comprised: Passive InfraRed sensors that measured activity as a binary event and air temperature $\left( \pm 0.47^{\circ} \mathrm{C}\right)$; current transducers which monitor power consumption by inferring current flow and 'smart plug' devices that monitor appliance electricity consumption $( \pm 10 \%)$.

The opening of windows and external doors were also recorded as a time stamp registering a binary event (open/close) through magnetic contact sensors and reported via the Zigbee system. A subset of windows were monitored in each house and these were selected based on discussion with the householders, being asked to select the window which was most frequently used in each room 

and doors monitored for each house. The window open time was calculated by aggregating the total number of hours of open time per day, from each window and external door divided by the total number of monitored channels.

Table 2: Number of channels used to monitor window and external door opening.

\begin{tabular}{lrrrrrr}
\hline Number of: & H05 & H10 & H30 & H37 & H39 & H46 \\
\hline Monitored windows & 6 & 4 & 9 & 8 & 3 & 8 \\
Monitored doors & 2 & 2 & 2 & 2 & 2 & 2 \\
Available data (days) & 82 & 68 & 132 & 64 & 37 & 131 \\
\hline
\end{tabular}

A filter was applied to the data to ensure that all measurement channels required for the calculations were available each day (Table 1). The systems used in this study were a combination of off-the-shelf and purpose made devices, and some were less reliable than others. Data was lost through loss of power in battery charged equipment and powered devices, including communication hubs being inadvertently switched off by householders. Further information can

\subsection{Sample description}

The properties were detached and semi-detached and constructed between 1930 and 1990 with typical brick and block wall construction and tiled roofs. Although a modest sample, they are representative of those found throughout the UK: owner occupied dwellings represent $64 \%$ of the UK population and cohabiting couples with dependent children account for $37 \%$ of the owner occupied dwellings (DCLG, 2016). The wider LEEDR sample was selected broadly around the following criteria:

- owner occupied family homes;

230

- have an interest in reducing their energy demand;

- be willing to have their homes monitored; and, 
Table 3: Summary of the building and household characteristics. ' $D$ ' and 'SD' denotes detached and semi-detached properties, all of which have 2 floors.

\begin{tabular}{|c|c|c|c|c|c|c|c|c|c|c|}
\hline $\begin{array}{l}\text { House } \\
\text { code }\end{array}$ & $\begin{array}{r}\text { Year } \\
\text { built }\end{array}$ & $\begin{array}{r}\text { House } \\
\text { type }\end{array}$ & $\begin{array}{r}\text { House } \\
\text { size } \\
\end{array}$ & $\begin{array}{l}\text { House } \\
\text { insulation }\end{array}$ & $\begin{array}{c}\text { Glazing } \\
\text { type }\end{array}$ & $\begin{array}{c}\text { Boiler } \\
\text { eff. }\end{array}$ & $\begin{array}{l}\text { Number of } \\
\text { appliances }\end{array}$ & $\begin{array}{l}\text { Number of } \\
\text { occupants }\end{array}$ & $\begin{array}{l}\text { Weekdays } \\
\text { occupied }\end{array}$ & $\begin{array}{r}\text { Indoor } \\
\text { temp. }\end{array}$ \\
\hline H05 & 1940 & SD & $117 \mathrm{~m}^{2}$ & Insulated cavity, loft $(200 \mathrm{~mm})$ & Double & $87 \%$ & 34 & 3 & 1 & $18.0^{\circ} \mathrm{C}$ \\
\hline H10 & 1980 & D & $167 \mathrm{~m}^{2}$ & Insulated cavity, loft $(>250)$ & Double & $90 \%$ & 39 & 4 & 5 & $19.0^{\circ} \mathrm{C}$ \\
\hline $\mathrm{H} 30$ & 1950 & D & $111 m^{2}$ & Solid wall, loft (none) & Single & $90 \%$ & 33 & 2 & 5 & $17.8^{\circ} \mathrm{C}$ \\
\hline $\mathrm{H} 37$ & 1970 & D & $140 \mathrm{~m}^{2}$ & Insulated cavity, loft $(150 \mathrm{~mm})$ & Double & $90 \%$ & 37 & 4 & 5 & $18.7^{\circ} \mathrm{C}$ \\
\hline H39 & 1950 & D & $110 \mathrm{~m}^{2}$ & Solid Wall, loft $(>250 \mathrm{~mm})$ & Double & $78 \%$ & 42 & 4 & 1 & $17.5^{\circ} \mathrm{C}$ \\
\hline H46 & 1990 & $\mathrm{SD}$ & $148 \mathrm{~m}^{2}$ & Insulated cavity, loft $(200 \mathrm{~mm})$ & Double & $91 \%$ & 49 & 6 & 5 & $21.2^{\circ} \mathrm{C}$ \\
\hline
\end{tabular}

- be willing to participate in recorded interviews and other activities.

A subset of six homes were selected for this study based on:

- availability of the requisite data;

- heating and hot water were delivered by combination boilers;

- a range of ages of construction types and internal conditions; and,

- a range of family sizes/ages.

The characteristics of the resultant sample are summarised in Table 3 Most households were occupied by at least one person throughout the week due to only one parent being in full time employment, or part-time working, working from home, retirement or unemployment. The sample includes a single parent family with one child (H30); a multi-generation family home with four children, parents and grandmother (H46); three houses with four family members (H10, H37, H39) and one house with three (H05). The home owners were in their late forties to late fifties and all were middle to high income families with education backgrounds up to post-graduate level.

Semi-structured interviews supplemented with informal communication were used to explore the ventilation practices in more detail. These were designed to encourage reflection on window and door use. A summary of the key characteristics that were reported were:

- H05 reported opening windows constantly (during night and day) and regularly opening the back door to 'allow the outside to come in' and to give 
the dog free run of the garden. Several windows were often continuously opened and the back door was opened for as long as 13 hours a day, when the space-heating was operational.

- H10 reported that they hardly ever open windows. The only window used was the bathroom window to let the water vapour out after showering or bathing but not if the weather was very cold, when a dehumidifier was used instead.

- H37 reported that they implemented a rigorous and structured ventilation strategy to 'air the house'. Windows were carefully selected and opened every day for around one hour, especially during the weekends. This activity was informed by one of the adult householders who was an expert in natural ventilation design and modelling.

- H46 reported opening bedroom windows in particular. This was driven by the need to reduce 'bad odour' and led to bedroom windows slightly opened for the whole day, only closing before going to bed.

These features are readily evident when window and door opening are plotted (Figure11. The orange bars show the front and back door operations and the blue, the windows in the key rooms in the homes. The total duration each element remains open every day was aggregated in hours and plotted as a single point (solid square surrounded by a square box). Repeated actions are shown by denser collections of points $\left(0-5 \mathrm{hday}^{-1}\right.$ for the front door in H05, for example). Some elements have two node clusters (H37: Bed.1), or even three (H46: Bed. 275

Figure 1 should be viewed in conjunction with Table 2 because the interpretation of the plot is affected by the number of samples available, 68 for H10 and 131 for H46, for example. However, the key features to draw attention to are: the extent of the opening of the back door and the general maintenance of open windows in H05; the lack of operation of the windows in H10; the regular, grouped and compact opening characteristics in H37; and significant opening 

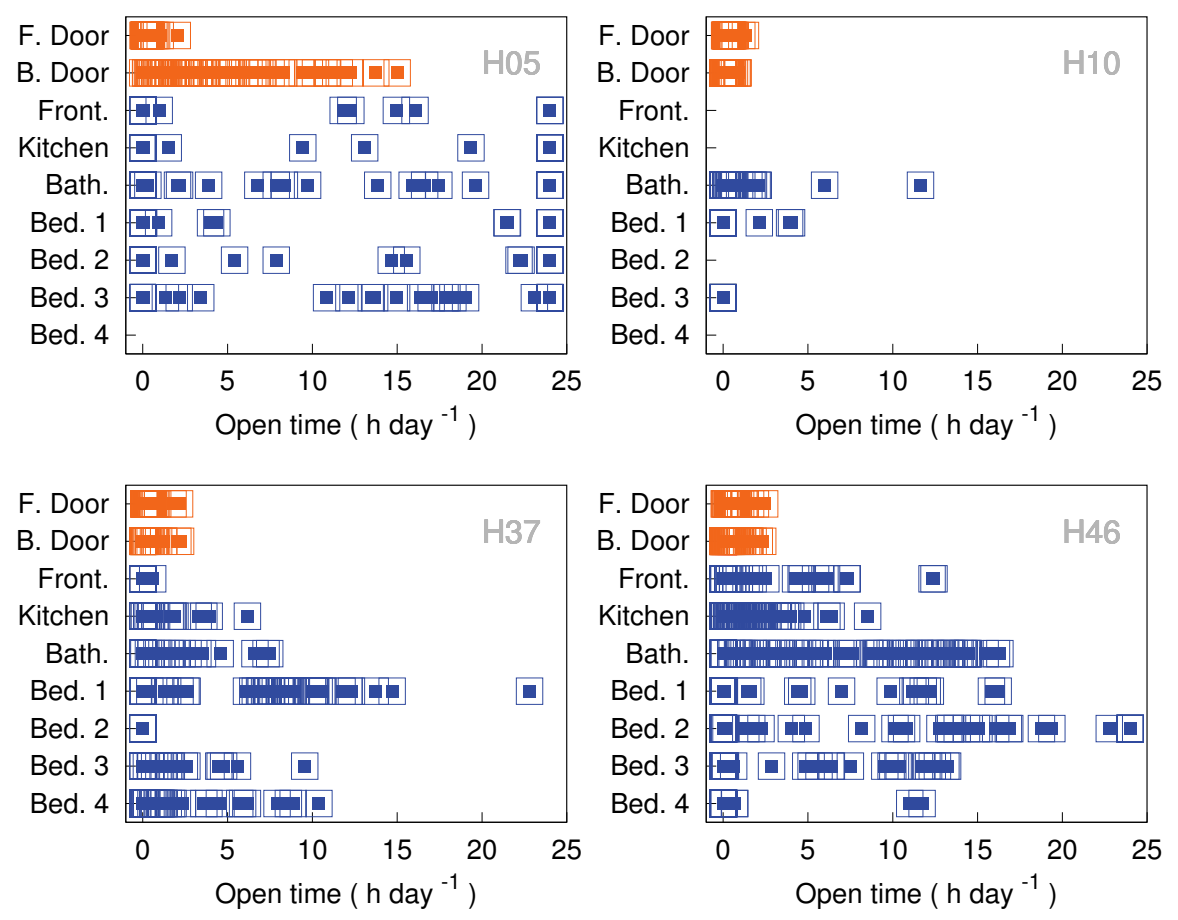

Figure 1: Window (blue) and door (orange) opening duration for H05, H10, H37 and H46 during the heating season in 2013.

activity in H46, particularly in the bedrooms.

\section{Evaluating the Hybrid-Heat Balance (HHB) method}

The work reported here formed part of a larger multi-disciplinary study to establish the landscape of daily life in the home as it relates to energy demand and demand reduction. A governing principle was to cause the least disturbance to the occupants as possible during the study, which combined with safety concerns (Gough et al., 2018), meant that intrusive methods of verifying/validating the method were impractical.

The approach taken was to estimate the daily mean ACRs for each day of available data in 2013 for each of the six households. The magnitude of 
these estimates were compared to established norms for these buildings and correlations of ACR with wind speed and window opening were verified against observed and reported behaviour from the interviews.

\subsection{Results}

Since the calculation (Equation 2 of $\bar{N}$ is dependent on the internal/external temperature difference and the sensitivity of the estimates to the available temperature difference was tested using uncertainty analysis. It was found that reliable results were generated when the temperature difference was greater than $5 \mathrm{~K}$. The practical implications of this are depicted in Figure 2 where the upper plot presents the daily mean outside air temperature (black line) and the daily mean internal air temperatures for all of the dwellings studied here (blue). The lower figure plots the temperature difference (orange) and the $5 \mathrm{~K}$ threshold (dashed line). The colder winter (to the left) can be seen, and this increases the temperature difference, as one might expect.

The days that fall below this line are rejected and these tend to be during summer and swing seasons. There is also evidence of heating systems being switched off over holiday periods (red circle), causing the internal temperatures to drop and the temperature difference to fall below the $5 \mathrm{~K}$ threshold. The implications for estimating $\bar{N}$ is that the bulk of the available data tends to be in the cooler months when the heating system is active.

\subsection{Estimates of $A C R$}

The minimum, maximum and average ACRs were calculated using the available data for each household over 2013 and are presented in Table 4 . Note that the number of data given in Table 2 are the total available for analysis after the $5 \mathrm{~K}$ criterion has been applied. The uncertainty in these values was calculated by propagating the uncertainty in the measurements and any parameter through the calculation (Coleman and Steele, 2018).

The average ACRs vary from $0.5 \mathrm{~h}^{-1}$ to $2.6 \mathrm{~h}^{-1}$ which corroborates the work of others (EST, 2014, Bedford et al. 1943, Fabi et al., 2012), and are within the 

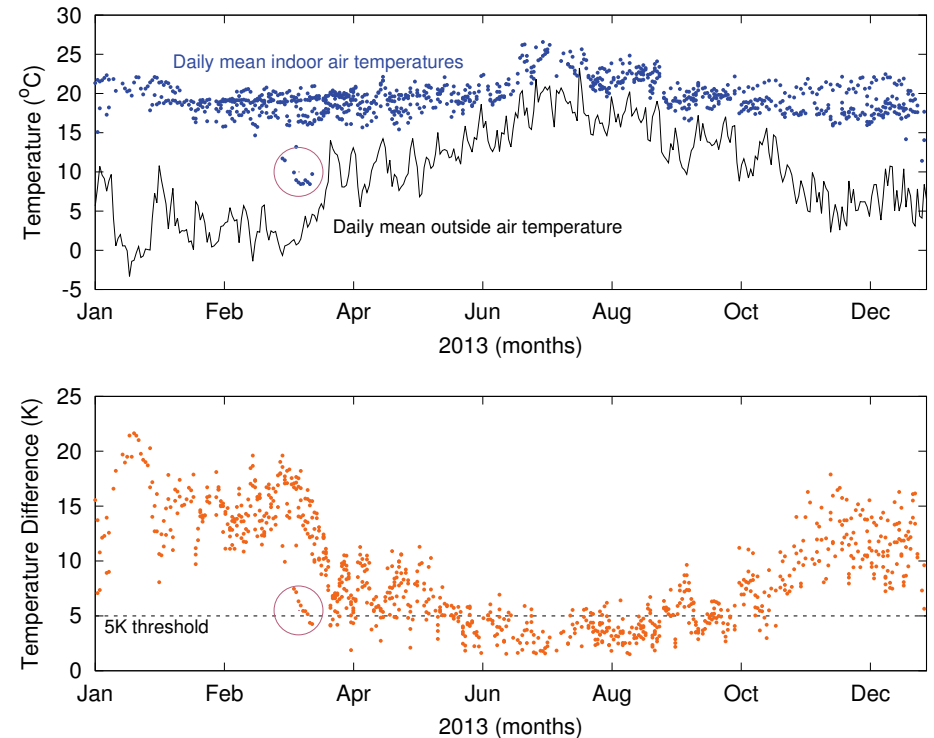

Figure 2: A comparison of the temperature difference between the daily mean indoor air temperature and the daily mean outdoor air temperature to the $5 \mathrm{~K}$ threshold, below which the difference is considered two small to yield reliable estimates of ACR. The upper plot gives the temperatures and the lower, the temperature differences with the threshold. The red circle highlights one house where the heating was switched off for a significant period, causing the internal temperatures to decay towards the external air temperature.

bounds of uncertainty of the estimates found by Wallace et al. (2002). Minimum values, when it might be expected that windows and doors are kept closed for the majority of the day, were below $0.1 \mathrm{~h}^{-1}$, although the uncertainty in these estimates is relatively high. The upper end of these limits might suggest that $0.4 \mathrm{~h}^{-1}$ to $1.3 \mathrm{~h}^{-1}$ are within the uncertainty in the minimum rates observed. Maximum values observed ranged from $1.2 \mathrm{~h}^{-1}$ in H10, a house who rarely opens windows to $9.8 \mathrm{~h}^{-1}$ in $\mathrm{H} 05$, who regularly have all windows open. High values (up to $30 \mathrm{~h}^{-1}$ ) have also been observed by Sheldon et al. (1989) and Bedford et al. (1943).

The ventilation model within BREDEM was used to calculate the daily mean ACR for each house on the same days as for the HHB method using the 
Table 4: Minimum, average and maximum ACRs $\left(\mathrm{h}^{-1}\right)$ estimated using the HHB method for the available data in 2013.

\begin{tabular}{cccc}
\hline Household & Minimum & Average & Maximum \\
\hline H05 & $<0.1 \pm 0.9$ & $2.4 \pm 0.4$ & $9.8 \pm 2.0$ \\
H10 & $<0.1 \pm 0.9$ & $0.5 \pm 0.3$ & $1.2 \pm 0.3$ \\
H30 & $<0.1 \pm 0.5$ & $1.9 \pm 0.6$ & $7.1 \pm 6.2$ \\
H37 & $<0.1 \pm 1.0$ & $2.1 \pm 1.4$ & $6.3 \pm 3.4$ \\
H39 & $<0.1 \pm 0.8$ & $2.0 \pm 0.6$ & $7.4 \pm 6.9$ \\
H46 & $<0.1 \pm 0.4$ & $0.6 \pm 0.3$ & $1.8 \pm 1.5$ \\
\hline
\end{tabular}

local daily mean wind speed measurements from the MIDAS weather station at Sutton Bonington to drive both calculations. The average ACRs from BREDEM were between $0.5 \mathrm{~h}^{-1}$ and $1.3 \mathrm{~h}^{-1}$. The households in this sample with higher ventilation rates were underestimated by BREDEM (H05, Table 4), and those who used less ventilation were overestimated (e.g. H10).

\subsection{ACR correlations}

Data from four households (H05, H10, H37 and H46) were plotted in two figures: one that gives ACR as a function of wind-speed (Figure 3 ) and the other as a function of window open time (Figure 4). Linear least squares regression has been used to characterise the relationships, represented by the blue line in both figures. The orange line in Figure 3 represents the equivalent ventilation characteristic as described by BREDEM adjusting for each building.

Although the correlations between ACR, wind speed and the duration of window opening are weak, there are observable differences between households. Three user types can by identified based on their use of windows: H10 (and H39) who rarely open windows (which we call here, rare operators); H37 and H46 (and H30), who open regularly 1-5 hours a day (regular operators) and H05 who opens frequently and for long periods (extended operators). The opening time influences the range of household ACRs, resulting in values between $0 \mathrm{~h}^{-1}$ 

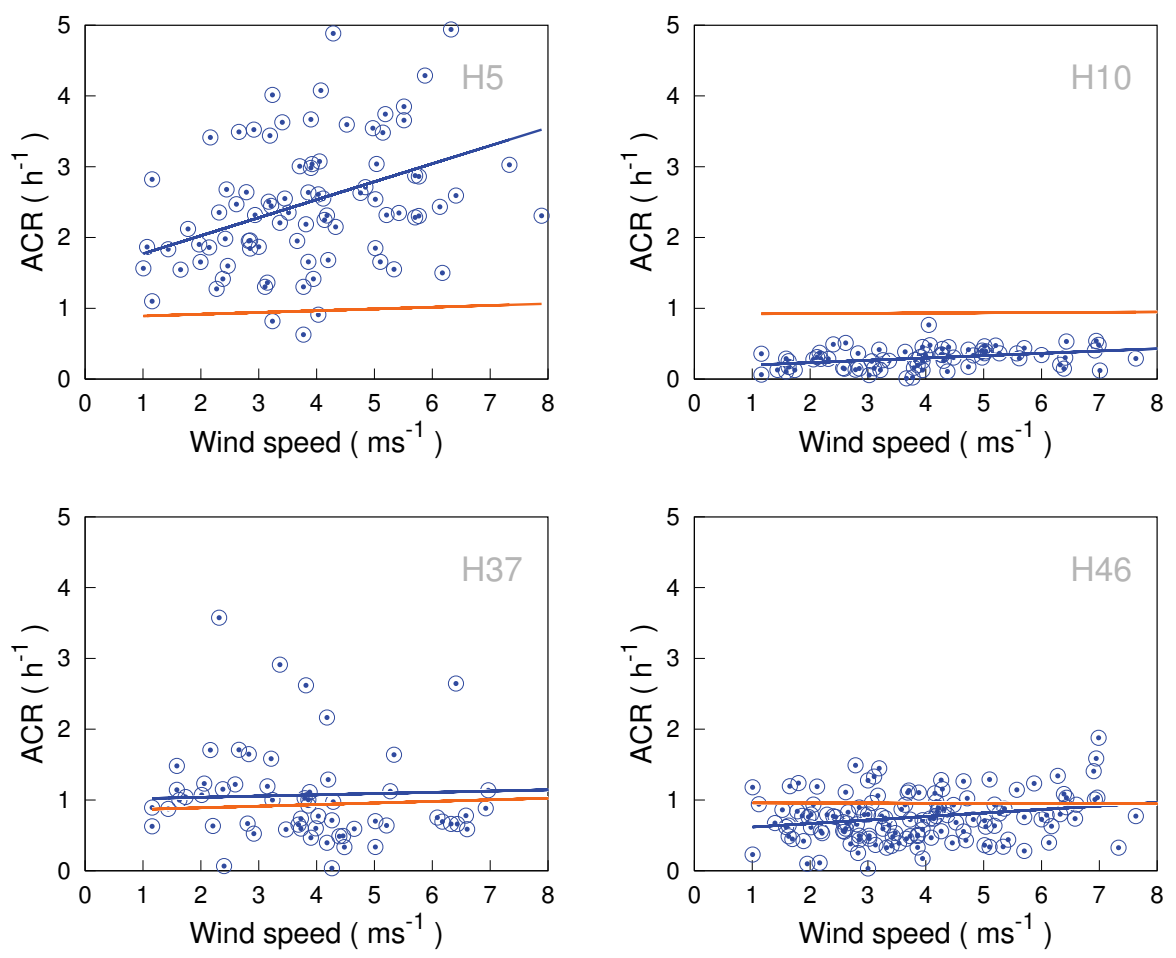

Figure 3: Correlation between ACR and wind speed. Linear regression least squares models shown as a blue line and the orange line is the equivalent model predicted according to BREDEM for the specific building type for each home.

and $1 \mathrm{~h}^{-1}$ for rare operator households, $0.5 \mathrm{~h}^{-1}$ to $2 \mathrm{~h}^{-1}$ for regular operators and $1.5 \mathrm{~h}^{-1}$ to $3 \mathrm{~h}^{-1}$ for the extended operator households.

This observation is in the line with previous research, which highlighted the strongest influence on ACR of window opening, reporting an increase of $2 \mathrm{~h}^{-1}$ for extended opening time (Wallace et al., 2002). H37 is the only house that shows any correlation with window operation. Two clusters of data around $1 \mathrm{~h}$ window $^{-1}$ and $2 \mathrm{hwindow}^{-1}$ are evident. By extrapolation this implies an infiltration rate of $0.78 \mathrm{~h}^{-1}$, which is similar to the average suggested by BREDEM, $0.7 \mathrm{~h}^{-1}$, and also the minimum ventilation rate for a healthy indoor environment

of similar characteristics (ODPM, 2010). 

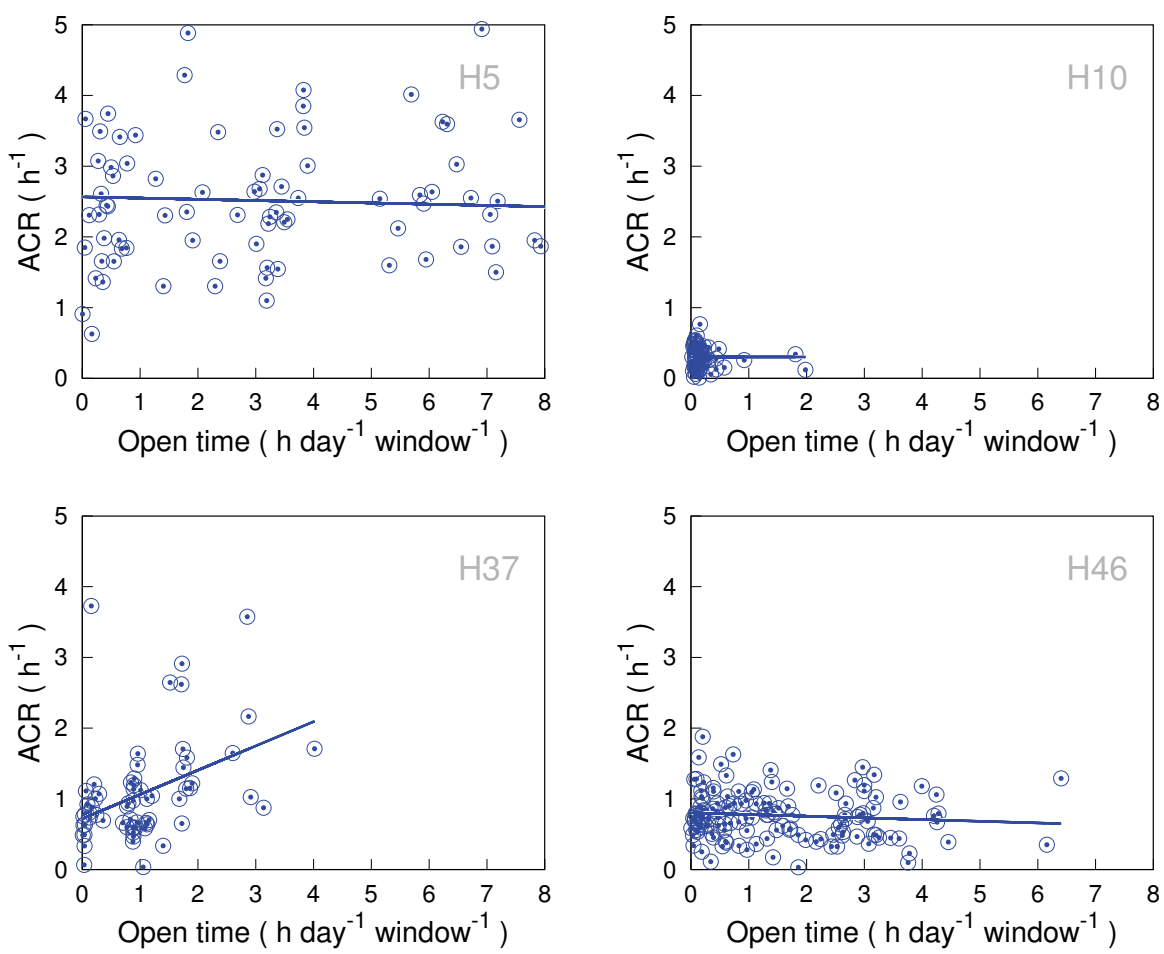

Figure 4: Correlation between $\mathrm{ACR}$ and window open time with a linear regression least squares model shown as a solid blue line.

\section{The impact of ventilation on household energy demand}

The HHB technique is applied here to a hypothetical energy demand reduction modelling exercise to demonstrate:

- the degree of customisation of analysis to individual households that can be generated;

- the potential for the dissaggregation of energy demand and householder reduction guidance that can be created; and,

- the scalability of the approach by mounting the method on pre-existing smart meter/home monitoring systems. 
A sample of homes were treated individually taking the state of the building as it was surveyed prior to the collection of the monitoring data and applying the energy demand reduction models to each specific case. The configuration of the smart monitoring devices in each home were different and hence the application of the method was not only adapted for the condition of the building fabric,

375 heating systems and the occupant activity, but also for the available data: a critical requirement needed to apply such a technique to many buildings.

\subsection{The approach to the analysis}

The analysis was based on data over a whole year (2013). The data available for the analysis varied between 100 days (H39) to 246 days (H46) out of 365, and so the results were scaled up to yield annual energy reduction values by averaging week day and weekend day values in six, two month periods (Jan/Feb, Mar/Apr, etc). These are then multiplied up by the appropriate number of days in the period such that the sum is over 365 days.

A literature review determined a list of interventions that impact building 385 energy demand and of these, four were selected to demonstrate the application of the method. These were minimising ventilation to provide the minimum stated in the building regulations, increasing the insulation levels of the building fabric to the current building regulations standards, installing triple glazing and heating the interior to a maximum temperature of $17^{\circ} \mathrm{C}$ (Boardman et al. 2005.

390 Ben and Steemers, 2014, DTI, 2007; Loveday et al., 2008; Energy Saving Trust, 2011; Shipworth et al., 2010; Hall et al., 2013, TSB, 2013; Banfill et al., 2011a, Mata et al. 2010, Boardman, 2007; DTI, 2007; Moon and Han, 2011, Martinaitis et al. 2015, Hong et al. 2006). Implementing the interventions to the stated levels are unlikely to be achieved in practice, but they represent what might be considered to be a 'theoretical limit' to energy demand reduction which allows the greatest potential impact to be evaluated.

The intervention models are applied to either the data components, or the modeled components of the approach as appropriate. Reducing space-heating set point temperature is applied to the measured room temperatures at the 
native sample interval of the data (1 minute in this case), which allows very specific effects of interventions to be represented. The filtered, or modified data is then aggregated/averaged to yield daily values and then used as the new input to the heat balance calculation in the HHB method. The upgrade of insulation and triple glazing were represented by adjusting the U-value parameters in the steady-state fabric heat loss calculation, were the appropriate heat losses are calculated on a daily basis, prior to the heat balance calculation. Adjustment to the ACR was implemented by modifying the daily estimates of $\bar{N}$.

The flexibility in the analysis the method offers is in the extent to which measures are applied in a particular household because it can be modified through the adjustment of the model parameters. In addition, because the data collected from each household implicitly captures their daily routines and activities, the analysis of the impact of any measure, or group of measures, are automatically tuned to that specific household. The analysis is executed in four stages:

1. Run the HHB method over the available data to derive $Q_{v}$ and then $\bar{N}$ for each day.

2. Apply intervention models to estimate the resultant energy consumption, first $Q_{e}^{\prime}$ (to account for internal heat gains) and then $Q_{g}^{\prime}$.

3. Calculate the daily energy reduction $Q_{g_{\text {reduction }}}=Q_{g}-Q_{g}^{\prime}$, and likewise $Q_{e}$.

4. If 365 days of data are not available, scale the reductions calculated on the available data up to yield an annual figure.

\subsection{Results}

The results from modelling each measure in isolation were ranked based on the average energy reduction achieved throughout the sample, Table 5 . The largest reductions for each house are highlighted in bold text. Wall insulation ranked first on average and minimising ventilation fifth. The impact of wall insulation was particularly high in two houses, H30 (30\% reduction) and H39 (64\% reduction), which are both detached properties with solid wall construction. Similar figures were found by Banfill et al. (2011b), suggesting a $60 \%$ to 
$71 \%$ potential reduction was possible by applying retrofit measures to a solid wall house. The difference in the potential reduction between these two solid wall houses might be partially attributed to larger impact of ventilation on H30, tempering the impact of the insulation.

Table 5: Ranking the energy demand reduction potential of each measure in isolation in each house. The figures show the reduction based on the 2013 data (MWh/year) and as a percentage (in parenthesis). The measures that yielded the largest reductions are identified in bold for each house.

\begin{tabular}{clrrrrrr}
\hline Rank & Reductions & H05 & H10 & H30 & H37 & H39 & H46 \\
\hline 1. & Fabric insulation & $2.7(10 \%)$ & $4.4(17 \%)$ & $\mathbf{9 . 8}(\mathbf{3 5 \%})$ & $3.3(13 \%)$ & $\mathbf{1 4 . 8}(\mathbf{6 2 \%})$ & $2.2(8 \%)$ \\
2. & Triple glazing & $2.4(9 \%)$ & $\mathbf{5 . 7 ( 2 2 \% )}$ & $5.9(21 \%)$ & $4.3(17 \%)$ & $3.4(14 \%)$ & $5.6(20 \%)$ \\
3. & Heating to $17^{\circ} \mathrm{C}$ & $4.8(18 \%)$ & $4.9(19 \%)$ & $3.9(14 \%)$ & $\mathbf{4 . 5}(\mathbf{1 8 \% )}$ & $2.2(9 \%)$ & $\mathbf{7 . 0 ( 2 5 \% )}$ \\
4. & Minimum ventilation & $\mathbf{8 . 4 ( 3 2 \% )}$ & $0.2(1 \%)$ & $4.7(17 \%)$ & $4.2(17 \%)$ & $1.2(5 \%)$ & $2.6(9 \%)$ \\
\hline
\end{tabular}

The replacement of windows with triple glazing could reduce energy consumption from $9 \%$ to up to $22 \%$. Similar reductions to those from triple glazing are possible from reducing the peak indoor temperature to $17^{\circ} \mathrm{C}$. In $\mathrm{H} 46$ the maximum reduction is generated by reducing their internal air set point temperature as the daily average air temperature in that home is over $21^{\circ} \mathrm{C}$ during the heating season, the highest in the sample.

The decrease of ventilation would have the largest impact for H05 (32\%), which might be expected given the amount of window operation observed (Figure 1). In H37, where windows were thoughtfully operated, a $17 \%$ reduction might be possible. The reduction is similar in H30 and H46, which could reduce their consumption by about $9 \%$. At the other extreme, H10 might only benefit from a $1 \%$ reduction, because the windows are rarely opened. In fact the analysis was rerun in H10 to represent sealing of gaps and cracks in the fabric and this intervention yielded a higher reduction of $3 \%$, which illustrates the diagnostic capabilities of the approach.

The results are plotted in Figure 5. The format of the plots were inspired by concept work carried out by Human Centered Design researchers collabo- 


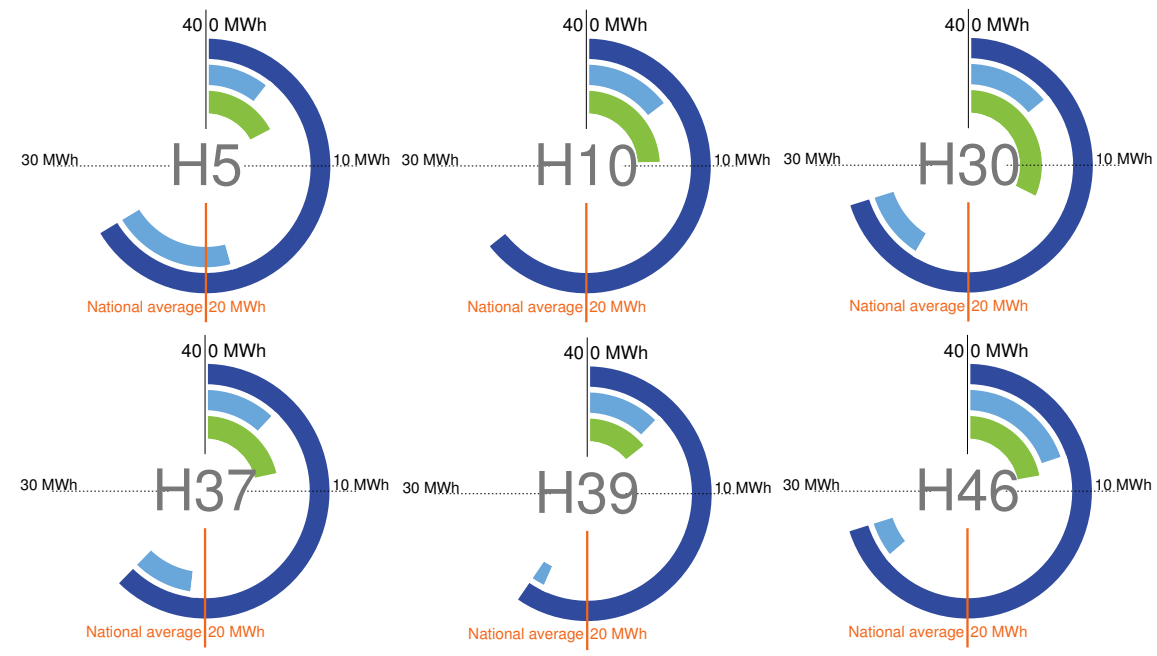

Figure 5: Household consumption and demand reduction data generated by applying the HHB method to six households. Total annual energy consumption is shown by the dark blue bar, the top-right, light blue bar indicates the proportion of the total that is electrical consumption. The other light blue bar (bottom-left) shows the impact of the ventilation reduction measure, and the green bar is the resultant consumption after all reduction measures have been applied.

rating on the LEEDR project (Buswell et al. (2015), p79). The dark blue bar indicates total energy consumption in 2013 and the top-right light blue bar is the proportion of that consumption that is electricity. The bottom-left light blue bar represents the heat energy lost through ventilation (over and above the minimum required for health). The green bar represents the resultant energy consumption if all reduction measures are applied. The national average of 20 MWh for this group of homes is shown by the orange line.

Plotting the data in this way allows the comparison of data important to the information to convey to the householder. In this case, including the total annual energy consumption demonstrates that this sample of six households use significantly more than the national average for their house type. Energy demand reduction and other useful targets can also be illustrated on the plot. Linking this graphical representation directly to the monitoring system database can 
provide visualisation of live and historical energy use, together with reduction potential which the householder can readily access to inform them of progress when trying to affect changes in their energy consumption.

\section{Discussion}

The HHB method has been demonstrated to provide indicative estimates of ACRs that are useful for creating more complete energy demand reduction analysis that can be individualised for a household through the use of monitoring data. Both the significance and the variability of ACR on energy consumption was demonstrated, underlining the need for its evaluation (Fabi et al., 2012, Carrilho et al., 2016).

ACRs are influenced by several driving forces: wind, (CIBSE, 2006); window opening (Fabi et al., 2012, Howard-Reed et al., 2002, Kvisgaard and Collet 1990, Wilson et al. 1996); house characteristics (CIBSE, 2006, EST, 2014); and behaviour (Zhai et al., 2015). Although the HHB method does not yield statistically significant correlations, it is capable of identifying those that use a significant amount of ventilation (H05), those who are particularly frugal (H10) and those in between (the majority). The method also appeared to be sensitive to differentiate the effects of the systematic operation of windows in H37 although the reasons for the lack of evidence of effect of window opening in the other houses could not be determined with certainty. One reason for this maybe in part connected to the impact of equalising temperatures on the reduction in air flow rate through reduced stack effect (limiting to about $2 \mathrm{~h}^{-1}$, Wallace et al. (2002)).

The HHB method is sensitive to the internal and external air temperature difference and a minimum $\Delta \mathrm{T}$ of $5 \mathrm{~K}$ is needed to yield reliable results. The ACRs are evaluated over a $24 \mathrm{~h}$ period to minimise the influence of thermal mass on the heat balance. Work undertaken in preparation of this article did explore the estimation of hourly ventilation rates and although there was potential, the results were less reliable and we suspect that the dampening effect of the thermal 
mass influenced the calculation.

The resultant ACRs in homes are affected by factors that the HHB method because it can characterise ventilation from non-intrusive data that implicitly captures the effect of window and door opening on space-conditioning energy 
consumption.

If the estimates of ACR for the sample presented here are taken at face value, there are potential implications for the attainment of health standards. (ODPM, 2010) suggest $0.5 \mathrm{~h}^{-1}$ is the minimum required, implying that all but H05 in this sample is under-ventilated for varying proportions of the year. In H10, only $7 \%$ of the days tested met this minimum criteria (excepting the limits 530 of uncertainty). A future application for the HHB method might be to alert the householder to potentially unhealthy ventilation practices and guide them in balancing this requirement with the need for minimising space-heating, a difficult trade off to maintain (Dimitroulopoulou, 2012).

The HHB method makes use of smart-meter and smart-home monitoring 535 data and does not require physical testing to estimate daily mean ACR. This makes it powerful as it can be used on-line to continually monitor ventilation and scalable as it can be applied to any house with requisite monitoring data. As the number of households that have smart monitoring and measurements grows, there is the potential to collect greater information on ACRs throughout the UK and beyond with the HHB method. As the home energy service market develops (DECC, 2012), monitoring and feedback to householders can now include information on ventilation control, which was previously not possible. As the population ages (Hamza and Gilroy, 2011), more of the population will live at home and the need for remote monitoring and balancing the trade of ${ }_{545}$ between energy for space-heating and indoor air quality and will become acute. Approaches like the HHB method could contribute to ensuring the health of nations (Deloitte, 2015).

Further work is needed to fully validate the approach, ideally comparing the results to multiple days of data derived from more conventional physical testing such as tracer gas methods. Work might also consider a more systematic evaluation of the influence of extractor fans and trickle vents. 


\section{Conclusions}

A new Hybrid-Heat Balance method that combines steady-state modelling with smart-home and smart-meter monitoring data in order to customise energy demonstrated that the approach yields credible estimates of daily mean ACRs in domestic buildings. These estimates can be combined with other analysis to create greater insights in home energy consumption and an example of how to apply the method to energy demand reduction analysis was given.

560 demand in the home and the approach demonstrated its sensitivity to identify both the significance and variation of ventilation in this process. Average ACRs calculated by the method were shown to vary between $0.5\left(\mathrm{~h}^{-1}\right)$ and $2.4\left(\mathrm{~h}^{-1}\right)$ and the subsequent energy demand can be nearly $60 \%$ of the daily demand for

\section{Acknowledgments}

This paper forms part of the work produced under the LEEDR: Low Effort Energy Demand Reduction Project based at Loughborough University, UK. The work was funded through the TEDDI call managed by the RCUK Digital Economy and Energy programmes (EPSRC Grant Number EP/I000267/1). The 
study and the journals' reviewers who's helpful and constructive comments had significant impact on the development of the article.

\section{References}

Abrahamse, W., Steg, L., 2009. How do socio-demographic and psychological factors relate to householders direct and indirect energy use and savings? Journal of Economic Psychology 30, 711-720.

Abrahamse, W., Steg, L., Vlek, C., Rothengatter, T., 2007. The effect of tailored information, goal setting, and tailored feedback on household energy use, energy-related behaviors, and behavioral antecedents. Journal of Environmental Psychology 27, 265-276.

ASTM, 2012. Standard guide for using indoor carbon dioxide concentrations to evaluate indoor air quality and ventilation: D6245-07. URL: www.astm.org.

Banfill, P.F., Simpson, S., Gillott, M.C., White, J., 2011a. The potential for energy saving in existing solid wall dwellings through mechanical ventilation and heat recovery. European Council for an Energy Efficient Economy, summer study , 6-031.

Banfill, P.F., Simpson, S.A., Gillott, M.C., White, J., 2011b. Mechanical ventilation and heat recovery for low carbon retrofitting in dwellings, in: World Renewable Energy Congress-Sweden; 8-13 May; 2011; Linköping; Sweden, Linköping University Electronic Press. pp. 1102-1109.

Baruah, P.J., Eyre, N., Qadrdan, M., Chaudry, M., Blainey, S., Hall, J.W., Jenkins, N., Tran, M., 2014. Energy system impacts from heat and transport electrification. Proceedings of the Institution of Civil Engineers-Energy 167, $139-151$.

Bedford, T., Warner, C., Chrenko, F., et al., 1943. Observations on the natural ventilation of dwellings. Journal of the royal institute of British architects 51, $7-11$. 
BEIS, 2017. Energy Consumption in the UK. Department for Business,

n Energy and Industrial Strategy. URL: https://www.gov.uk/government/ statistics/energy-consumption-in-the-uk

Ben, H., Steemers, K., 2014. Energy retrofit and occupant behaviour in protected housing: A case study of the brunswick centre in london. Energy and Buildings 80, 120-130.

BEng, D.J., et al., 2003. A physically-based energy and carbon dioxide emission model of the UK housing stock. Ph.D. thesis. Leeds Metropolitan University.

Boardman, B., 2007. Home Truths: A low-carbon strategy to reduce UK housing emissions by $80 \%$ by 2050 . Environmental Change Institute, University of Oxford.

Boardman, B., Darby, S., Killip, G., Hinnells, M., Jardine, C.N., Palmer, J., Sinden, G., Lane, K., Layberry, R., Wright, A., et al., 2005. $40 \%$ house .

Buswell, R., Webb, L., Cosar-Jorda, P., Marini, D., Brownlee, S., Thomson, M., Yang, S.H., Kalawsky, R., 2018. LEEDR project home a energy dataset URL: https://figshare.com/articles/LEEDR_project_ home_energy_dataset/6176450, doi:10.17028/rd.lboro.6176450.v1.

Buswell, R., Webb, L., Mitchell, V., Mackley, K.L., 2017. Multidisciplinary research: should effort be the measure of success? Build-

ם ing Research \& Information 45, 539-555. URL: https://doi.org/ 10.1080/09613218.2016.1194601, doi 10.1080/09613218.2016.1194601, arXiv:https://doi.org/10.1080/09613218.2016.1194601.

Buswell, R., Webb, L., Quiggin, D., Cosar-Jorda, P., Marini, D., Osz, K., Morosanu, R., Pink, S., Leder Mackley, K., Wilson, G., T., Hanratty, M., Mitchell, V., Bhamra, T., 2015. Leedr: What are the results? partici1] pant feedback for h99. URL: https://dspace.lboro.ac.uk/dspace-jspui/ handle/2134/18528. 
Buswell, R.A., 2013. Uncertainty in whole house monitoring URL: https: //dspace.lboro.ac.uk/dspace-jspui/handle/2134/13144.

Buswell, R.A., Marini, D., Webb, L., Thomson, M., 2013. Determining heat use in residential buildings using high resolution gas and domestic hot water monitoring .

${ }_{640}$ Carrilho, J.D., Gomes, M.R., Mateus, M., Batterman, S., Silva, M.G.d., 2016. Measurement of infiltration rates from the daily cycle of ambient $\mathrm{CO}_{2}$. International Journal of Ventilation 14, 409-420.

Chenari, B., Carrilho, J.D., da Silva, M.G., 2016. Towards sustainable, energy-efficient and healthy ventilation strategies in buildings: A review. Renewable and Sustainable Energy Reviews 59, 1426

- 1447. URL: http://www.sciencedirect.com/science/article/pii/ S1364032116001040, doi/https://doi.org/10.1016/j.rser.2016.01.074

CIBSE, 2005. Guide B: Heating, ventilating, air conditioning and refrigeration. The Chartered Institution of Building Services Engineers, London .

650 CIBSE, 2006. Guide A : Environmental design. The Chartered Institution of Building Services Engineers, London .

Clegg, S., Mancarella, P., 2018. Integrated electricity-heat-gas modelling and assessment, with applications to the great britain system. part ii: Transmission network analysis and low carbon technology and resilience case studies. Energy .

Coleman, H.W., Steele, W.G., 2018. Experimentation, validation, and uncertainty analysis for engineers. John Wiley \& Sons.

Cosar-Jorda, P., Buswell, R.A., 2015. Estimating the air change rates in dwellings using a heat balance approach. Energy Procedia 78, ${ }_{660} \quad 573$ - 578. URL: http://www.sciencedirect.com/science/article/ 口 pii/S1876610215024704, doi/https://doi.org/10.1016/j.egypro.2015. 11.738. 6th International Building Physics Conference, IBPC 2015. 
Coxon, R., 2013. Research into the effect of improving air tightness in a typical uk dwelling. BUILDING AND DUCTWORK AIRTIGHTNESS SELECTED PAPERS FROM THE REHVA SPECIAL JOURNAL ISSUE ON AIRTIGHTNESS , 19.

DCLG, 2016. English housing survey headline report 2014-2015. URL:

[1]

a system/uploads/attachment_data/file/501065/EHS_Headline_report_ 2014-15.pdf.

DECC, 2012. Smart metering implementation programme. URL: https:

1] //assets.publishing.service.gov.uk/government/uploads/system/

a uploads/attachment_data/file/641254/FINAL_non_dom_dcc_opt_out_ government_response_to_the_April_2016_further_consultation.pdf.

DECC, 2017. Energy consumption in the united kingdom.

Deloitte, 2015. Digital health in the uk: An industry study for the office of life science.

Dick, J., et al., 1949. Experimental studies in natural ventilation of houses. Journal of the Institution of Heating and Ventilating Engineers 17, 420-52.

Dietz, R.N., Goodrich, R.W., Cote, E.A., Wieser, R.F., 1986. Detailed description and performance of a passive perfluorocarbon tracer system for building ventilation and air exchange measurements, in: Measured air leakage of buildings. ASTM international.

Dimitroulopoulou, C., 2012. Ventilation in european dwellings: A review. Building and Environment 47, 109-125.

Djunaedy, E., Hensen, J.L., Loomans, M., 2003. Toward external coupling of building energy and airflow modeling programs. ASHRAE Transactions 109, $771-787$.

DTI, U., 2007. Meeting the energy challenge:a white paper on energy. 

thermostats-and-controls accessed:2018-07-11.

EST, 2014. Draught proofing. URL: http://www.energysavingtrust.org. uk/home-insulation/draught-proofing. accessed: 2018-07-11.

Eyre, N., Baruah, P., 2014. Uncertainties in energy de-

a mand in residential heating. doi www.ukerc.ac.uk/asset/ 6A83A900-3FB0-47F8-BD4DA206DFFC61D1/.

Fabi, V., Andersen, R.V., Corgnati, S., Olesen, B.W., 2012. Occupants' window opening behaviour: A literature review of factors influencing occupant behaviour and models. Building and Environment 58, 188-198.

Gough, H., Luo, Z., Halios, C., King, M.F., Noakes, C., Grimmond, C., Barlow, J., Hoxey, R., Quinn, A., 2018. Field measurement of natural ventilation rate in an idealised full-scale building located in a staggered urban array: Comparison between tracer gas and pressure-based methods. Building and Environment 137, 246 - 256. URL: http: //www.sciencedirect.com/science/article/pii/S0360132318301902, doi:https://doi.org/10.1016/j.buildenv.2018.03.055.

Grot, R.A., 1979. Air leakage characteristics and weatherization techniques for low-income housing, in: Proceedings of DOE/ASHRAE Conference on Exterior Envelops of Buildings, 1979, pp. 178-194.

Haldi, F., Robinson, D., 2011. The impact of occupants' behaviour on building energy demand. Journal of Building Performance Simulation 4, 323-338.

Hall, M.R., Casey, S.P., Loveday, D.L., Gillott, M., 2013. Analysis of uk domestic building retrofit scenarios based on the e.on retrofit research house using energetic hygrothermics simulation - energy efficiency, indoor air quality, occupant comfort, and mould growth potential. Building and Environment 70, $48-59$. 
Hamza, N., Gilroy, R., 2011. The challenge to uk energy policy: An ageing population perspective on energy saving measures and consumption. Energy Policy 39, 782 - 789. URL: http://www.sciencedirect.com/science/article/ pii/S0301421510008037 doi:https://doi.org/10.1016/j.enpol.2010. 10.052. special Section on Offshore wind power planning, economics and environment.

Hargreaves, T., 2018. Beyond energy feedback. Building Research \& Information $46,332-342$.

Henderson, J., Hart, J., 2012. Bredem 2012, a technical description of the bre domestic energy model .

Herrero, S.T., Nicholls, L., Strengers, Y., 2018. Smart home technologies in everyday life: do they address key energy challenges in ${ }_{730}$ households? Current Opinion in Environmental Sustainability 31,

a 65 - 70. URL: http://www.sciencedirect.com/science/article/

1. pii/S1877343517300891, doi/https://doi.org/10.1016/j.cosust.2017. 12.001. sustainability governance and transformation 2018.

HHG, 2018. Home heating guide: boiler efficiency tables. URL: https://www . homeheatingguide.co.uk/efficiency-tables. accessed: 2014-03-31.

Hong, S.H., Oreszczyn, T., Ridley, I., Group, W.F.S., 2006. The impact of energy efficient refurbishment on the space heating fuel consumption in english dwellings. Energy and Buildings 38, 1171-1181.

Hosni, M.H., Jones, B.W., Xu, H., 1999. Experimental results for heat gain and radiant/convective split from equipment in buildings. ASHRAE Transactions $105,527-539$.

Howard-Reed, C., Wallace, L.A., Ott, W.R., 2002. The effect of opening windows on air change rates in two homes. Journal of the Air \& Waste Management Association 52, 147-159. 
ISO, I., 2012. 12569: 2012: Thermal performance of buildings and materialsdetermination of specific airflow rate in buildingstracer gas dilution method. International Organization for Standardization: Geneva, Switzerland, 54.

Kane, T., Firth, S.K., Lomas, K.J., 2015. How are uk homes heated? a citywide, socio-technical survey and implications for energy modelling. Energy and Buildings 86, 817-832.

Kvisgaard, B., Collet, P., 1990. The user's influence on air change, in: Air change rate and airtightness in buildings. ASTM International.

Lipschultz, R., 1981. Infiltration and indoor air quality in energy efficient houses in Eugene, Oregon .

Liu, Y., Misztal, P.K., Xiong, J., Tian, Y., Arata, C., Nazaroff, W.W., Goldstein, A.H., 2018. Detailed investigation of ventilation rates and airflow patterns in a northern california residence. Indoor air .

Loveday, D.L., Bhamra, T., Tang, T., Haines, V.J.A., Holmes, M.J., Green, R.J., 2008. The energy and monetary implications of the 24/7 always on society. Energy Policy 36, 4639-4645.

Marley, W., 1935. The measurement of the rate of air change. J. Instn Heat. Vent. Engrs, Lond 2, 499.

Martinaitis, V., Zavadskas, E.K., Motuzien, V., Vilutien, T., 2015. Importance of occupancy information when simulating energy demand of energy efficient house: A case study. Energy and Buildings 101, 64-75.

Mata, E., Kalagasidis, A.S., Johnsson, F., 2010. Assessment of retrofit measures for reduced energy use in residential building stockssimplified costs calculation, in: Proceedings of Sustainable Building Conference SB10mad. 28-30 April 2010, Madrid, Spain.

770 Moon, J.W., Han, S.H., 2011. Thermostat strategies impact on energy consumption in residential buildings. Energy and Buildings 43, 338-346. 
Nationalgrid, 2018. National grid uk. URL: https://www.nationalgrid.com/ uk/gas/market-operations-and-data/calorific-value-cv, accessed: 2018-07-11.

ODPM, 2010. The building regulations 2006 (F): Ventilation, Approved document.

Omrani, S., Garcia-Hansen, V., Capra, B., Drogemuller, R., 2017. Natural ventilation in multi-storey buildings: Design process and review of eval-

uation tools. Building and Environment 116, 182 - 194. URL: http: //wWW.sciencedirect.com/science/article/pii/S0360132317300720, doi:https ://doi.org/10.1016/j.buildenv.2017.02.012.

Persily, A.K., 1997. Evaluating building IAQ and ventilation with indoor carbon dioxide.

Persily, A.K., 2016. Field measurement of ventilation rates. Indoor Air 26, 97-111.

Pink, S., Mackley, K.L., Moroşanu, R., 2015. Hanging out at home: Laundry as a thread and texture of everyday life. International Journal of Cultural Studies 18, 209-224.

Sheldon, L., Hartwell, T., Cox, B., Sickles, J., Pellizzari, E., Smith, M., Perritt, R., Jones, S., 1989. An investigation of infiltration and indoor air quality. New York State Energy Res. Develop. Authority, Albany, NY, USA, Tech. Rep. NYSERDA-90-11 ON 191001298.

Sherman, M., 1989. Analysis of errors associated with passive ventilation measurement techniques. Building and Environment 24, 131-139. mas, K.J., 2010. Central heating thermostat settings and timing: building demographics. Building Research and Information 38, 50-69. 
Shove, E., Warde, A., 2002. Inconspicuous consumption: the sociology of consumption, lifestyles, and the environment. Sociological theory and the environment: classical foundations, contemporary insights 230 .

Southall, R., 2018. An assessment of the potential of supply-side ventilation demand control to regulate natural ventilation flow patterns and reduce domestic space heating consumption. Energy and Buildings 168,

a 201 - 214. URL: http://www.sciencedirect.com/science/article/pii/ S0378778817333054 doi/https://doi.org/10.1016/j.enbuild.2018.03. 005.

TSB, 2013. Retrofit revealed: The retrofit for the future projects-data analysis report.

Wallace, L., Emmerich, S., Howard-Reed, C., Dr, L.C., 2002. Continuous measurements of air change rates in an occupied house for 1 year: the effect of temperature, wind, fans, and windows. Journal of exposure analysis and environmental epidemiology 12, 296-306.

Warner, C.G., 1940. Measurements of the ventilation of dwellings. Epidemiology \& Infection 40, 125-153.

${ }_{815}$ Wei, S., Jones, R., de Wilde, P., 2014. Driving factors for occupant-controlled space heating in residential buildings. Energy and Buildings 70, 36-44.

Wilson, A., Colome, S., Tian, Y., Becker, E., Baker, P., Behrens, D., Billick, I., Garrison, C., 1996. California residential air exchange rates and residence volumes. Journal of Exposure Analysis and Environmental Epidemiology 6, $311-326$.

Wilson, G.T., Lilley, D., Bhamra, T., 2013. Design feedback interventions for n household energy consumption reduction URL: https://dspace.lboro.ac. uk/dspace-jspui/handle/2134/12522. 
Yu, Z., Fung, B.C., Haghighat, F., Yoshino, H., Morofsky, E., 2011. A systematic procedure to study the influence of occupant behavior on building energy consumption. Energy and Buildings 43, 1409-1417.

Yun, G.Y., Steemers, K., 2008. Time-dependent occupant behaviour models of window control in summer. Building and Environment 43, 1471 -

1 1482. URL: http://www.sciencedirect.com/science/article/pii/ 830 S036013230700159X doi https://doi.org/10.1016/j.buildenv.2007. 08.001 .

Zhai, Z.J., El Mankibi, M., Zoubir, A., 2015. Review of natural ventilation models. Energy Procedia 78, 2700-2705. 